\title{
Modelling the impact of future climate scenarios on yield and yield variability of grapevine
}

\author{
M. Bindi ${ }^{1, *}$, L. Fibbi ${ }^{2}$, B. Gozzini ${ }^{2}$, S. Orlandini ${ }^{2}$, F. Miglietta ${ }^{3}$ \\ ${ }^{1}$ DAPE-University of Florence and ${ }^{3}$ IATA-CNR, P. le delle Cascine 18, I-50144 Florence, Italy \\ ${ }^{2}$ CeSIA, Accademia dei Georgofili, Logge Ufíizi Corti, I-50122 Florence, Italy
}

\begin{abstract}
A mechanistic growth model was used to evaluate the mean yield and yield variability of grapevine Vitis vinifera $\mathrm{L}$. under current and future climates. The model used was previously validated using field experiment data. The effect of elevated $\mathrm{CO}_{2}$ on grapevine growth was also considered. Adaptation of 2 varieties (Sangiovese and Cabernet Sauvignon) to scenarios of increased $\mathrm{CO}_{2}$ and climate change, and potential changes in agricultural risk (i.e. inter-seasonal variability), were examined. Before testing the effect of climate scenarios, we analysed the sensitivity of modelled grapevine yield to arbitrary changes in the 3 driving variables (temperature, solar radiation and $\mathrm{CO}_{2}$ ). The results showed the model to be more sensitive to changes in $\mathrm{CO}_{2}$ concentration and temperature than to changes in radiation. Analyses made using transient GCM (general circulation model) scenarios (UKTR and GFDL) showed different changes in mean fruit dry matter for the different scenarios, whereas mean total dry matter, and fruit and total dry matter variability, were predicted to increase under almost all the scenarios. Predictions based on equilibrium scenarios (UKLO and UKHI) gave similar results. For Sangiovese, variety adaptation analysis suggested a better adaptation in terms of mean production, but a worse adaptation in terms of yield variability.
\end{abstract}

KEY WORDS: Grapevine cv. Sangiovese $c \mathrm{cv}$. Cabernet Sauvignon - Climate change GCM scenarios - Agricultural risk

\section{INTRODUCTION}

Grapevine (Vitis vinifera L.) is a woody perennial plant that reaches reproductive maturity in 4 to $5 \mathrm{yr}$, and may remain economically productive for 50 to 60 yr. Budbreak occurs annually over a characteristic range of variety-specific dates (from March to April) and is followed by a period of intensive vegetative growth during which the shoots arising from the buds elongate and produce leaves very rapidly. Vegetative growth usually slows when flowering of the 1 to 3 clusters on each shoot begins. Relative earliness or lateness of budbreak for a variety depends upon weather patterns. The number of viable fruits (berries) that continue development is determined shortly after flowering, at which time the maturing fruit clusters become the primary sinks for photosynthate. Ripening fruits

\footnotetext{
•E-mail: bindi@sunserver.iata.fi.chr.it
}

undergo 2 growth phases: (1) seed development and the building of the hard, green berry structure and (2) sugar accumulation, colour change, and rapid enlargement, the start of which is called veraison. Full maturity, depending upon the variety and the site, is typically reached during August to September in the Northern Hemisphere.

Growth and development of grapevine are influenced by environmental factors such as temperature and radiation, which make this crop sensitive to climate change. However, photosynthesis and growth are also stimulated by increasing $\mathrm{CO}_{2}$ concentration (Kimball et al. 1993, Rogers \& Dahlman 1993) and such an increase may result in greater accumulation of fruit and total biomass.

Preliminary studies on the effects of climate change on shifts in the areas suitable for grapevine growth have been carried out coupling the information from general circulation models (GCMs), or historical datasets, with current knowledge about the environmental 
constraints that delimit the areas of grapevine cultivation (Kenny \& Harrison 1992, Orlandini et al. 1993). For more detailed predictions on growth and yield of grapevine (as well as of other crops) under climate change, deterministic simulation models are used (see Kenny et al. 1993 and Harrison et al. 1995 for reviews). Models provide tools that allow us to use the hypotheses generated from experimental studies to simulate plant responses to novel climatic conditions, in order to understand the major climate change effects and to define appropriate measures for dealing with such changes.

To date, no predictions are available on potential changes in mean yield and yield variability of grapevine resulting from global environmental change. In this study, the effects of increasing $\mathrm{CO}_{2}$ concentration, and of changes in temperature and radiation, on yield of grapevine were simulated with a simple mechanistic crop growth model. Field data obtained from a Free Air Carbon dioxide Enrichment (FACE) experiment were used for model parameterization under conditions of elevated $\mathrm{CO}_{2}$. Synthetically gener-

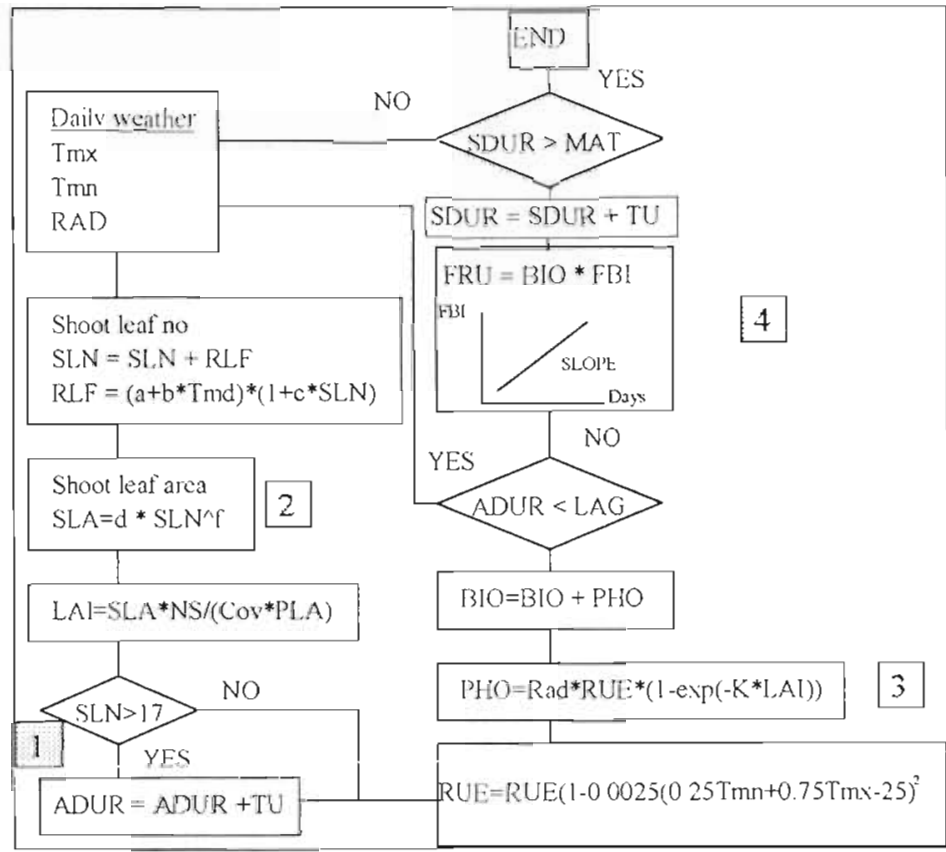

Fig. 1. Flow diagram of the model for simulating growth and yield of grapevine. The main processes simulated are: (1) crop ontogeny; (2) leaf development; (3) biomass accumulation; (4) fruit growth. See text for explanation; symbols are defined in Table 1 ated weather data for a location in northern

Italy, and site-specific equilibrium scenarios (UKHI and UKLO) and transient scenarios (UKTR and GFDL), were used as the baseline climate and as future climate scenarios, respectively. Therefore, mean yield and yield variability of 2 varieties (Sangiovese and Cabernet Sauvignon) were examined in terms of crop response characteristics across the years simulated.

\section{MATERIALS AND METHODS}

\subsection{Model description}

A simplified approach, recently used to study the influence of environmental parameters on the growth and yield of several crop types - soybean (Spaeth et al. 1987), maize (Muchow et al. 1990), and wheat (Amir \& Sinclair 1991) - was used to develop a simple mechanistic model of grapevine crop growth (Bindi et al. 1995a). In this model, relatively few relationships are required to describe the development, growth and yield of grapevine (Fig. 1; symbols used in the model are defined in Table 1). The major processes simulated are the following:

Ontogeny. Crop ontogeny is divided in 2 periods: the development period between budbreak and bloom and the fruit growth period between bloom and maturity. The duration of the period between budbreak and bloom is calculated assuming that bloom occurs when a fixed number of leaves (17) have appeared on the main shoot (Coombe 1988). Using this approach, the duration mainly depends on the rate of leaf appearance which is, in turn, a function of temperature and crop ontogeny (Miglietta et al. 1992). The duration of the period between bloom and maturity (MAT) is assumed to be strictly temperature-dependent and, accordingly, it is calculated using accumulated degree days (SDUR, Fig. 1). This period is divided into 2 subphases which are the period between bloom and the beginning of active fruit growth and the period in which fruits are actively growing.

Leaf area. Leaf area is estimated on the basis of the total number of actively growing shoots per unit area and the rate of leaf appearance and expansion. The rate of leaf appearance is calculated using a model proposed by Miglietta et al. (1992). This model calculates the daily rate of leaf formation and emission (RLF) after budbreak on the basis of the mean daily temperature, assuming that the rate of leaf appearance declines during ontogeny (Fig 1). The leaf area growth (SLA) is then estimated as a function of the total number of emerged leaves using an empirical relationship similar to those found for other crops (wheat, barley, etc.) (Fig. 1).

Biomass accumulation. Leaf area is used to calculate the amount of solar radiation intercepted by the leaf 
canopy so that crop biomass accumulation ( $\mathrm{PHO}$ ) can be calculated on the basis of crop radiation use efficiency (RUE, biomass accumulated per unit solar radiation intercepted) (Fig. 1). Moreover, following the approach used in other simulation models (Ritchie \& Otter 1984, van Keulen \& Seligman 1987) the effect of low and high temperature on carbon uptake is introduced in the form of a second order function decreasing RUE for suboptimal temperature (Fig. 1).

Fruit growth. Daily fruit growth rate is calculated assuming that the fruit biomass index (FBI) increases linearly during fruit growth (Fig. 1). This index is calculated as the ratio of fruit dry weight (i.e. berries) to the current year's growing total biomass dry weight (i.e. leaves, stems, grape-stalks and berries). A linear relationship between the ratio of seed to total aboveground biomass (harvest index) and time has already been observed for several species (Spaeth et al. 1987. Muchow et al. 1990, Amir \& Sinclair 1991). Grapevine did not provide an exception to this even when fruit, rather than seed biomass, was considered (Bindi et al. 1995a).

The model was recently calibrated and validated for 2 grapevine varieties (Sangiovese and Cabernet Sauvignon) using data from field trials conducted from 1992 to 1994 in the central Italian region of Chianti (Bindi et al. 1995a). In these field experiments growth and final yield were recorded; field data from the first season were used to calibrate the model and those from the remaining 2 seasons for validation. The model accurately predicted total biomass and fruit accumulation in both years (Fig. 2, Table 2).

\section{2. $\mathrm{CO}_{2}$ effects}

A recent experiment conducted using a sophisticated fumigation technology (Bindi et al. 1995b) showed that elevated atmospheric $\mathrm{CO}_{2}$ levels had a positive effect on grapevine growth. Such an effect was reflected by an
Table 1. Definition of symbols used in the grapevine crop growth model

\begin{tabular}{|c|c|c|}
\hline Variable & Description & Value or unit \\
\hline \multicolumn{3}{|c|}{ State variables } \\
\hline ADUR & Accumulated Tu durng the lag phase & ${ }^{\circ} \mathrm{C}$ \\
\hline $\mathrm{BIO}$ & Total biomass dry matter & $g m^{-2}$ \\
\hline FBI & Fruit biomass index & (unitless) \\
\hline FRU & Fruit biomass dry matter & $g \mathrm{~m}^{-2}$ \\
\hline LAl & Leaf area index & $m^{2}$ leaf $m^{-2}$ \\
\hline SDUR & $\begin{array}{l}\text { Accumulated TU during the fruit } \\
\text { growth phase }\end{array}$ & ${ }^{\circ} \mathrm{C}$ \\
\hline SLN & Shoot leaf number & number \\
\hline SLA & Shoot leaf area & $\mathrm{m}^{2}$ \\
\hline \multicolumn{3}{|c|}{ Other variables } \\
\hline $\mathrm{PHO}$ & Daily photosynthesis & $\mathrm{g} \mathrm{m}^{-2} \mathrm{~d}^{-1}$ \\
\hline RLF & Rate of leaf formation & leaves $d^{-1}$ \\
\hline TU & Thermal unit $\left(\mathrm{Tmd}-\mathrm{Tb}, \mathrm{Tb}=10^{\circ} \mathrm{C}\right)$ & ${ }^{\circ} \mathrm{C} \mathrm{d}^{-1}$ \\
\hline \multicolumn{3}{|c|}{ Plant parameters } \\
\hline$a, b, c$ & Coefficients in SLN equation & $-0.28,0.04,-0.015$ \\
\hline$d, f$ & Coefficients in SLA equation & $5.39,2.13$ \\
\hline Cov & $\begin{array}{l}\text { Proportion of area shaded by } \\
\text { the plant }\end{array}$ & 0.75 \\
\hline RUE & Radiation use efficiency & $1.001^{\mathrm{d}}, 0.691^{b} \mathrm{~g} \mathrm{MJ}^{-1}$ \\
\hline K & Extinction coefficient of canopy & 0.5 \\
\hline LAG & Duration of lag phase in TU & $40^{\circ} \mathrm{C}$ \\
\hline MAT & Duration of fruit growth phase in TU & $1240^{\circ} \mathrm{C}$ \\
\hline NS & Number of shoots per plant & 11 \\
\hline PLA & Planting density & $3 \mathrm{~m}^{2}$ per plant \\
\hline SLOPE & Rate of change in FBI & $0.00443^{\mathrm{a}}, 0.00328^{\mathrm{b}} \mathrm{d}^{-1}$ \\
\hline \multicolumn{3}{|c|}{ Environmental variables } \\
\hline RAD & Daily solar global radiation & $M J m^{-2} d^{-1}$ \\
\hline Tind & Mean daily temperature & ${ }^{\circ} \mathrm{C}$ \\
\hline $\operatorname{Tmn}$ & Minimum daily temperature & ${ }^{\circ} \mathrm{C}$ \\
\hline $\operatorname{Tm} x$ & Maximum daily temperature & ${ }^{\circ} \mathrm{C}$ \\
\hline
\end{tabular}

Table 2. Mean bias error (MBE) and root mean square error (RMSE) between simulated (sim) and observed (obs) values of biomass components for 2 grapevine varieties

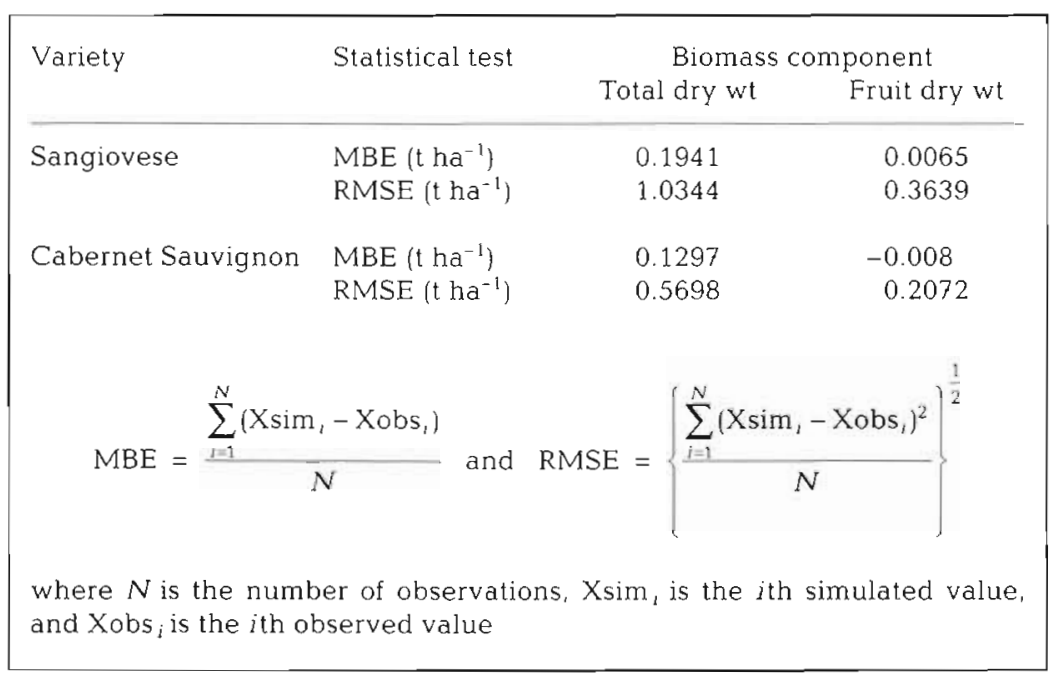



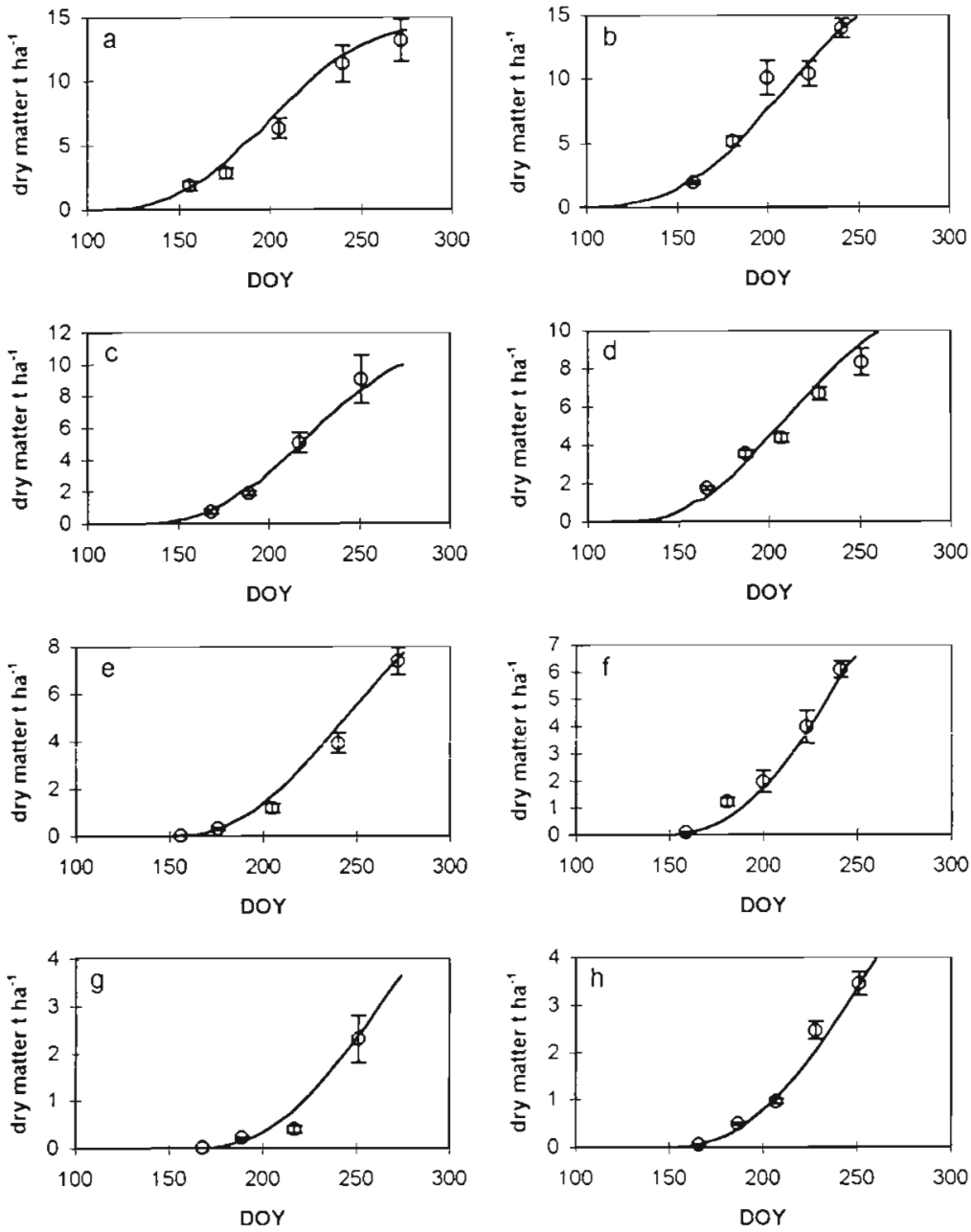

Fig. 2. Time course (DOY: day of year) of the total biomass (a-d) and fruit $(\mathrm{e}-\mathrm{h})$ dry matter $\left(\mathrm{tha} \mathrm{a}^{-1}\right)$, either observed $(\mathrm{O})$ or simulated by the model $(-)$ for $c v$. Sangiovese $(a-b, e-f)$ and $c v$. Cabernet $S .(c-d, g-h)$ in the $1993(a, c$, e, g) and 1994 (b, d, f, h) seasons

overall increase in the ratio of intercepted radiation to biomass accumulation (RUE). Accordingly, increased RUE was used to take the $\mathrm{CO}_{2}$ effect on growth into account. Assuming that RUE increased linearly $10.1 \%$ ppmv ${ }^{-1}$ ) with increasing atmospheric $\mathrm{CO}_{2}$ concentration $\left(\left[\mathrm{CO}_{2}\right]\right)$, RUE values for climate change scenarios were calculated as:

$$
\operatorname{RUE}_{\left.\mid \mathrm{CO}_{2}\right]}=\operatorname{RUE}_{[353]} \times\left\{1+a\left(\left[\mathrm{CO}_{2}\right]-353\right)\right\}
$$

where $a$ is a constant, 0.001 ppmv $^{-1}$.

None of the other model parameters was considered to be substantially affected by elevated $\mathrm{CO}_{2}$ concentrations.

\subsection{Model experiments}

The effects of climate change on potential grapevine production were studied at the northern Italian site of
Bologna (lat. $44.52^{\circ} \mathrm{N}$, long. $11.30^{\circ} \mathrm{E}$ ). Two grapevine varieties [cultivars (CV.) Sangiovese and Cabernet Sauvignon] were selected to examine the ability of these varieties to adapt to scenarios of increased $\mathrm{CO}_{2}$ and climate change, and the potential changes in agricultural risk (i.e, inter-seasonal variability). These varieties were chosen for their peculiar characteristics: the former is a highproduction variety, used in general for producing light wine, and the latter is a low-production variety, used for producing high quality wine.

Firstly, a sensitivity analysis of the model to independent changes in the 3 driving variables (temperature, solar radiation and $\mathrm{CO}_{2}$ concentration) was made on $c v$. Sangiovese using the baseline climate conditions. Variables were adjusted independently, in a stepwise manner, in order to evaluate the sensitivity of model results to changing values of each variable.

Subsequently, future climate scenario analyses were made for the 2 varieties running the model for both current and future climatic conditions. Current and future climate datasets for time periods of 31 yr were produced with the LARS-WG stochastic weather generator (Racsko et al. 1991, Barrow \& Semenov 1995) on the basis of historical weather data and of GCM output. The output of 2 types of scenario was used: equilibrium scenarios (UKLO, UKHI) and transient scenarios (UKTR and GFDL). For the transient scenarios 2 different model decades were used. For the UKTR scenario these were decades 31-40 and 66-75, and for GFDL decades 25-34 and 55-64. For the UKLO and GFDL scenarios the baseline variability in temperature was retained in the scenario data, whereas for the UKHI and UKTR6675 scenarios both the baseline variability and variability calculated from the GCM experiments were used. The scenarios with changed variability are denoted with a small ' $v$ ' in the scenario name (e.g. UKHIV). The atmospheric $\mathrm{CO}_{2}$ concentration was set to 353 ppmv for the baseline climate, and to 560 ppmv for the equilibrium GCM scenarios. The $\mathrm{CO}_{2}$ concentration of the first and second transient model decades was set to 454 and 617 ppmv, respectively, corresponding to the IPCC IS92a emission scenario. The emission scenario is denoted with a small ' $a$ ' in the scenario name (e.g. GFDL5564a). Details of the construction of site-specific scenarios are given in Barrow et al. (1995). 
For both these analyses the direct effect of increasing atmospheric $\mathrm{CO}_{2}$ concentration on the $\mathrm{CO}_{2}$ assimilation and growth of grapevine was incorporated.

Based on experimental observations (Calo' 1970) the onset of the growing season was held constant across years at 13 April [day of year (DOY) 103] in the sensitivity analysis, whereas in the scenario experiments the onset of the growing season was assumed to be variable, so as to take into account temperature increases which could favour an earlier budbreak. In the latter case, according to the results of a recent study performed for evaluating the reliability of different bio-climatic indicators (such as degree days, cumulative maximum temperature, cumulative radiation and cumulative temperature difference) for the prediction of the onset of the growing season (Bindi et al. 1995a), the date of budbreak was calculated as a function of cumulative temperature differences (CTD) from 1 January. Based on this criterion, budbreak took place when CTD reached $895^{\circ} \mathrm{C}$ for $\mathrm{Cv}$. Sangiovese and $993^{\circ} \mathrm{C}$ for $\mathrm{Cv}$. Cabernet Sauvignon, respectively. All other parameters defining crop characteristics were held constant (Bindi et al, 1995a).

The following output variables from the model were compared: duration of development phases (in days), fruit dry matter (t ha ${ }^{-1}$ ), total dry matter from the current year's growth ( $\mathrm{h} \mathrm{h}^{-1}$ ), and their coefficient of variations ( $\mathrm{CV}, \%)$. For each output variable, reported values are the mean results of 31 yr of crop growth simulations. Moreover, for a more detailed analysis of year-to-year variability, simulation results for the various scenarios were plotted as cumulative distribution plots (CDP). The CDP for these data were obtained by graphing the number of years exceeding a fruit production level against fruit production (Sinclair \& Rawlins 1993). As production increases on the abscissa in the plots, the number of years exceeding that yield level declines. At very low levels of fruit production all years exceeded the production on the abscissa, while at very high levels few, if any, years exceeded the production on the abscissa. Consequently, the CDP has a negative slope, with a less steep negative slope indicating greater variability in yield among years. A constant slope with a shift to the right or left indicates that mean yield has changed while yield variability has remained unchanged.

\section{RESULTS}

\subsection{Sensitivity analyses}

Simulated mean dry matter of fruit and total biomass for the baseline response were $6.62 \mathrm{t} \mathrm{ha}^{-1}$ and $15.09 \mathrm{t}$
Table 3. Sensitivity response of mean value and $\mathrm{CV}$ of total and fruit dry matter to different $\mathrm{CO}_{2}$ concentrations and solar radiation

\begin{tabular}{|c|c|c|c|c|}
\hline \multirow[t]{2}{*}{$\begin{array}{l}\text { Driving } \\
\text { variable }\end{array}$} & \multicolumn{2}{|c|}{$\begin{array}{l}\text { Final fruat dry wt } \\
\qquad\left(\mathrm{t} h \mathrm{a}^{-1}\right)\end{array}$} & \multicolumn{2}{|c|}{$\begin{array}{l}\text { Final total dry wt } \\
\qquad\left(t \mathrm{ha}^{-1}\right)\end{array}$} \\
\hline & Mean & $C V(\%)$ & Mean & CV $(\%)$ \\
\hline \multicolumn{5}{|l|}{$\mathrm{CO}_{2}$} \\
\hline 350 ppmv & 6.62 & 12.11 & 15.09 & 11.37 \\
\hline $550 \mathrm{ppmv}$ & 7.95 & 12.57 & 18.11 & 11.02 \\
\hline 700 ppmv & 8.94 & 12.36 & 20.37 & 11.54 \\
\hline \multicolumn{5}{|c|}{ Solar radiation } \\
\hline$-20 \%$ & 5.30 & 12.23 & 12.07 & 11.25 \\
\hline$+0 \%$ & 6.62 & 12.11 & 15.09 & 11.37 \\
\hline$+20 \%$ & 7.95 & 12.76 & 18.11 & 11.64 \\
\hline
\end{tabular}

ha ${ }^{-1}$, respectively (Table 3 ). The simulated CV for the 31 yr period was $12.11 \%$ for fruit and $11.37 \%$ for total dry matter (Table 3)

As expected the model predicted a positive and almost linear response of fruit and total dry matter to an increase in $\mathrm{CO}_{2}$ concentration from 350 to $700 \mathrm{ppmv}$ (Table 3) with about a $36 \%$ increase in fruit dry matter and a $34 \%$ increase in total dry matter. The CV of fruit and total dry matter remained almost unchanged (Table 3) and the predicted CV for total dry matter was always lower than that for fruit dry matter.

The model predicted that increased temperatures substantially reduced fruit and total dry matter (Fig. 3A). CV for both fruit and total dry matter increased with temperature, with the $\mathrm{CV}$ of fruit dry matter being larger than that for total dry matter (Fig. 3B). This is expected, as an increase in temperature shortens the duration of the growing season and, in particular, the duration of ripening. However, warmer temperatures early in the season lead to both an earlier and faster increase in leaf area, with a positive effect on biomass accumulation; these also cause a shift in development so that the same growth phases occur in different radiation regimes. This would have either positive or negative effects on yield if, all other things being equal, the ripening period coincided with a period of high or low radiation input.

The response of the model to $\pm 20 \%$ changes in the amount of daily radiation was positive and almost linear (Table 3), with changes in radiation having a more marked effect on total dry matter than on final fruit yield. Increasing radiation did not lead to changes in $\mathrm{CV}$ of either component (Table 3). Taking into account that the change in amount of radiation predicted by future scenarios is about $6 \%$ (see Fig. 6B), it can be concluded that this change will have a small impact on grapevine yields under a greenhouse climate. 

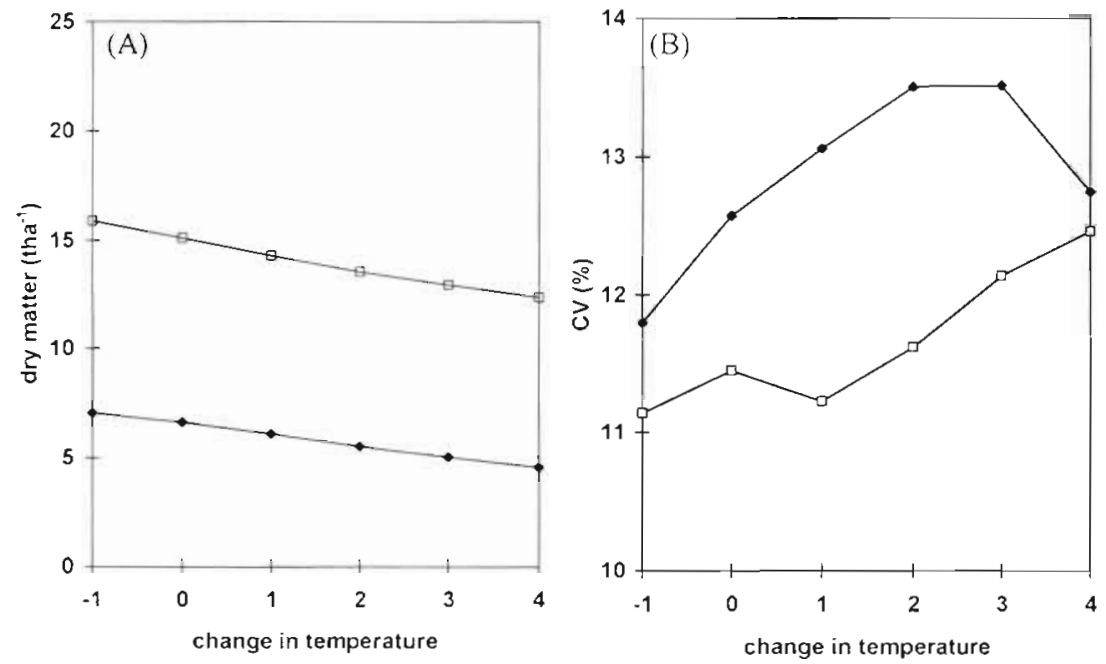

Fig. 3. Sensitivity response of the mean value (A) and coefficient of variation (B) of fruit $(\bullet)$ and total $(\square)$ dry matter (cv. Sangiovese) to different changes in temperature

\subsection{Climate change scenario analysis}

The mean duration from budbreak to maturity for the $31 \mathrm{yr}$ baseline climate for $\mathrm{cv}$. Sangiovese was $147 \mathrm{~d}$ (Table 4), which was $7 \mathrm{~d}$ longer than the same period for cv. Cabernet S. (Table 5); the duration from bloom to maturity was comparable for the 2 varieties (Tables $4 \& 5$ ). Mean fruit and total dry matter at maturity for $\mathrm{cv}$. Sangiovese were 6.48 and $14.71 \mathrm{t} \mathrm{ha}^{-1}$, which were 2.94 and $4.57 \mathrm{t} \mathrm{ha}^{-1}$ higher

Table 4. Mean and CV of several model outputs with climate scenarios for cV. Sangiovese

\begin{tabular}{|c|c|c|c|c|c|c|c|c|}
\hline \multirow[t]{2}{*}{ Scenario } & \multicolumn{2}{|c|}{$\begin{array}{l}\text { Bloom to maturity } \\
\text { (d) }\end{array}$} & \multicolumn{2}{|c|}{$\begin{array}{l}\text { Budbreak to maturity } \\
\text { (d) }\end{array}$} & \multicolumn{2}{|c|}{$\begin{array}{l}\text { Final fruit dry wt } \\
\qquad\left(\mathrm{t} \mathrm{ha} \mathrm{a}^{-1}\right)\end{array}$} & \multicolumn{2}{|c|}{$\begin{array}{l}\text { Final total dry wt } \\
\qquad\left(\mathrm{t} \mathrm{ha}^{-1}\right)\end{array}$} \\
\hline & Mean & CV $(\%)$ & Mean & CV $(\%)$ & Mean & CV $(\%)$ & Mean & $\mathrm{CV}(\%)$ \\
\hline 1. Baseline & 100 & 5.2 & 147 & 4.7 & 6.48 & 5.8 & 14.71 & 5.0 \\
\hline 2. UKHIV & 76 & 5.6 & 120 & 3.8 & 5.70 & 15.3 & 16.02 & 10.4 \\
\hline 3. UKHI & 74 & 6.0 & 120 & 4.3 & 5.35 & 12.5 & 15.43 & 7.8 \\
\hline 4. UKLO & 79 & 5.1 & 124 & 4.2 & 5.75 & 10.2 & 15.46 & 6.2 \\
\hline 5. UKTR3140a & 85 & 4.9 & 135 & 4.9 & 7.19 & 8.5 & 18.05 & 5.1 \\
\hline 6. UKTR6675a & 74 & 5.6 & 122 & 5.0 & 5.40 & 10.7 & 15.54 & 6.26 \\
\hline 7. UKTR6675av & 75 & 6.6 & 121 & 5.7 & 5.46 & 15.2 & 15.57 & 10.6 \\
\hline 8. GFDL2534a & 88 & 4.6 & 135 & 4.2 & 7.96 & 8.4 & 19.31 & 4.8 \\
\hline 9. GFDL5564a & 87 & 5.1 & 135 & 4.3 & 7.15 & 9.3 & 17.43 & 5.2 \\
\hline
\end{tabular}

Table 5. Mean and CV of several model outputs with climate scenarios for cv. Cabernet Sauvignon

\begin{tabular}{|c|c|c|c|c|c|c|c|c|}
\hline \multirow[t]{2}{*}{ Scenario } & \multicolumn{2}{|c|}{$\begin{array}{l}\text { Bloom to maturity } \\
\text { (d) }\end{array}$} & \multicolumn{2}{|c|}{$\begin{array}{l}\text { Budbreak to maturity } \\
\text { (d) }\end{array}$} & \multicolumn{2}{|c|}{$\begin{array}{l}\text { Final fruit dry wt } \\
\qquad\left(t h a^{-1}\right)\end{array}$} & \multicolumn{2}{|c|}{$\begin{array}{l}\text { Final total dry wt } \\
\qquad\left(t h a^{-1}\right)\end{array}$} \\
\hline & Mean & CV $(\%)$ & Mean & $\mathrm{CV}(\%)$ & Mean & $\operatorname{CV}(\%)$ & Mean & CV $(\%)$ \\
\hline 1. Baseline & 100 & 6.6 & 140 & 5.9 & 3.54 & 11.0 & 10.14 & 5.7 \\
\hline 2. UKHIV & 71. & 5.5 & 111 & 3.8 & 2.68 & 15.3 & 10.75 & 10.7 \\
\hline 3. UKHI & 70 & 6.1 & 110 & 4.3 & 2.52 & 12.8 & 10.36 & 7.8 \\
\hline 4. UKLO & 76 & 5.0 & 114 & 4.3 & 2.78 & 10.1 & 10.45 & 6.2 \\
\hline 5. UKTR3140a & 83 & 3.8 & 125 & 4.3 & 3.62 & 7.8 & 12.42 & 4.7 \\
\hline 6. UKTR6675a & 71 & 4.7 & 112 & 5.0 & 2.51 & 10.0 & 10.51 & 6.6 \\
\hline 7. UKTR6675av & 72 & 6.2 & 111 & 5.9 & 2.64 & 15.7 & 1.0 .49 & 11.1 \\
\hline 8. GFDL2534a & 86 & 4.8 & 128 & 4.7 & 4.02 & 8.8 & 13.24 & 4.9 \\
\hline 9. GFDL5564a & 85 & 4.4 & 126 & 4.0 & 3.51 & 8.2 & 11.88 & 5.0 \\
\hline
\end{tabular}


than those for $c v$. Cabernet $S$. (Tables $4 \& 5$ ). The variability of these means was greater for cv. Cabernet S, than for $\mathrm{Cv}$. Sangiovese. The CV of the time from budbreak to maturity was $4.7 \%$ for CV. Sangiovese compared with $5.9 \%$ for cv. Cabernet $\mathrm{S}$., whereas the CV of fruit dry matter was $5.8 \%$ and $11 \%$ for $\mathrm{CV}$. Sangiovese and Cabernet S., respectively (Tables 4 \& 5).

\subsubsection{Equilibrium scenarios}

The large increase in temperature in both equilibrium scenarios decreased the growth phase durations of bath varieties compared with the baseline climate (Tables 4 \& 5, Figs. 4 \& 5: Scenarios 2 to 4 ). The greatest reductions (of $19 \%$ and $21 \%$ for Sangiovese and Cabernet S., respectively) in the mean duration from budbreak to maturity were for the UKHI scenarios (Fig. 4) and were associated with the larger temperature changes predicted in these scenarios compared with UKLO (Fig. 6A). In general, the variability of crop durations was smaller for both varieties in future scenarios compared with that of baseline durations (Figs. 4 \& 5). These changes in variability were greater for $\mathrm{cv}$. Cabernet $\mathrm{S}$. in almost all equilibrium scenarios (Figs. 4 \& 5).

The shorter crop durations with all scenarios resulted in a $11-17 \%$ and $21-29 \%$ reduction of fruit dry matter for cv. Sangiovese and cv. Cabernet S., respectively (Fig. 7). However, total dry matter was greater compared with the baseline in both varieties (Fig. 8). This was due to the fact that shorter crop duration was more than compensated for by the positive effect of increased $\mathrm{CO}_{2}$ concentration and solar radiation pattern (Fig. 6B) in terms of total biomass accumulation, though not in terms of fruit accumulation. This different behaviour of the 2 components is essentially associated with the reduction of final FBI under future climate scenarios (Fig. 9) caused by shorter fruit growth periods (Fig. 5). The variability of mean fruit and total dry matter increased in almost all scenarios, and was greater for cv. Sangiovese than cv. Cabernet S. (Figs. $7 \& 8$ ).
Fig. 4. Relative changes in the mean value $(A, C)$ and coefficient of variation $(B, D)$ of the duration from budbreak to maturity compared to the baseline climate, as predicted by the climate scenarios for $\mathrm{cv}$. Sangiovese (A, B) and cv. Cabernet S. (C, D)
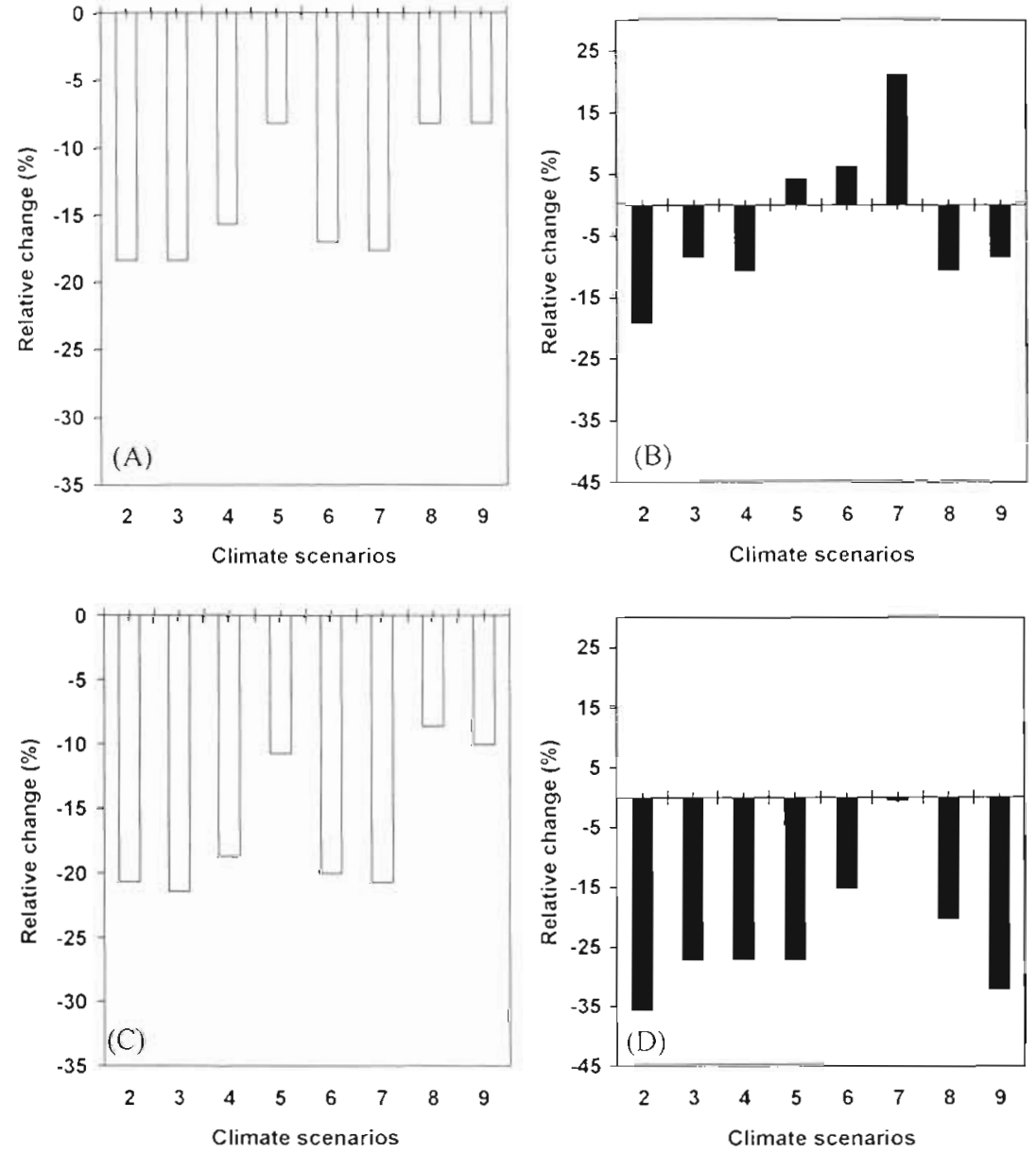

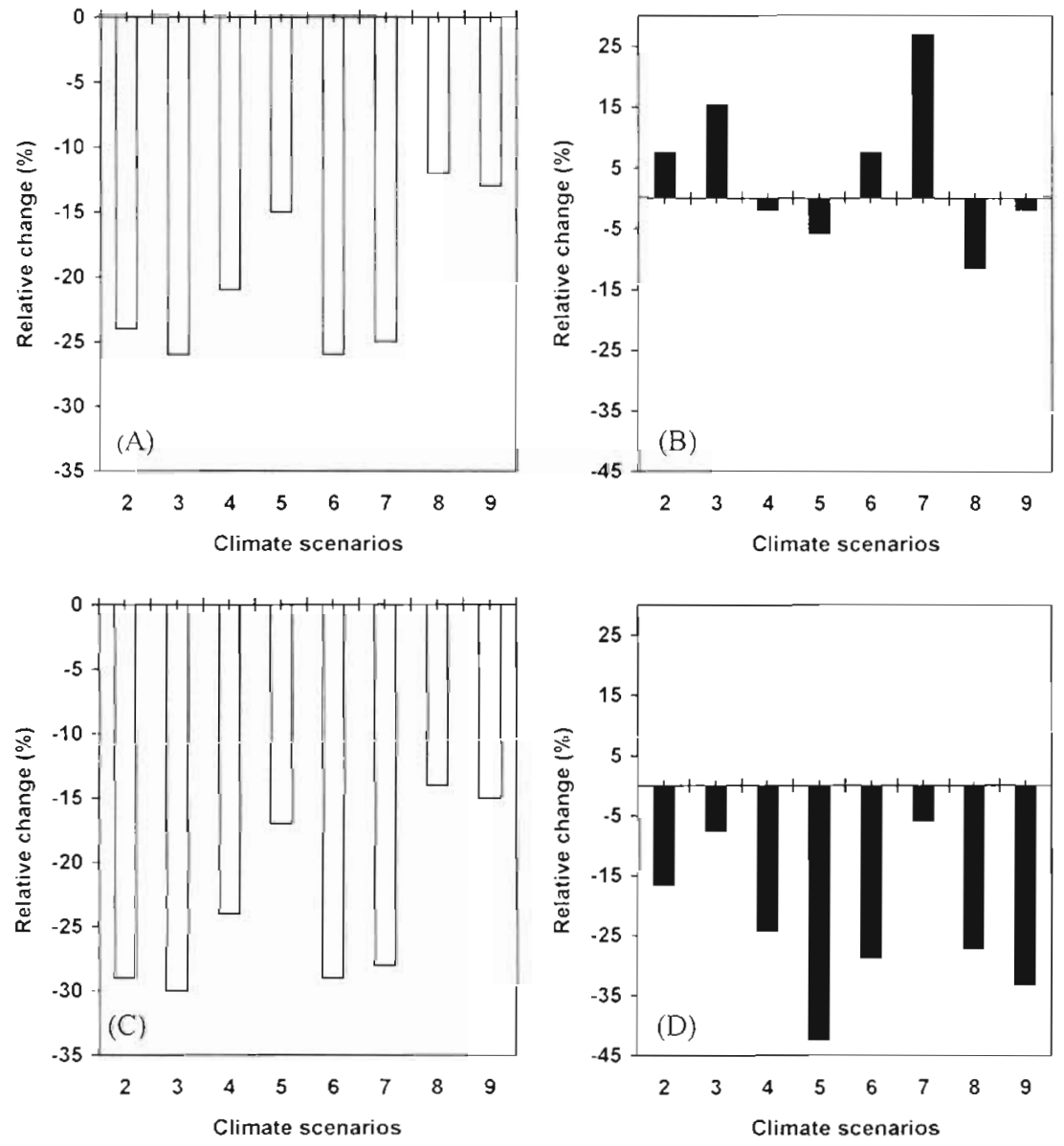

Fig. 5. Relative changes in the mean value $(A, C)$ and coefficient of variation $(B, D)$ of the duration from bloom to maturity compared to the baseline climate, as predicted by the climate scenarios for CV. Sangiovese (A, B) and $\mathrm{Cv}$. Cabernet $\mathrm{S}$. (C, D)

\subsubsection{Transient scenarios}

Growth phase durations of both varieties were reduced in all 5 transient scenarios compared with the baseline climate (Tables 4 \& 5; Figs. 4 \& 5: Scenarios 5 to 9$)$. The variability of these durations was always lower than with the baseline climate for $\mathrm{cv}$. Cabernet S. (Figs. $4 \& 5$ ), whereas no steady changes were detectable for phase durations of cv. Sangiovese (Figs. 4
\& 5). Despite this reduction in phase duration, $\mathrm{CO}_{2}$ effects caused an increase in total dry matter in all scenarios with respect to baseline (Fig. 8). In particular, $\mathrm{CO}_{2}$ effects did compensate, in half of the scenarios (Fig. 7), for the shorter fruit ripening time (Fig. 5) and the reduced final FBI under increased temperatures (Fig. 9). The variability in growth components was always higher than the baseline for cv. Sangiovese, with only 1 exception (Figs. $7 \& 8$ ); there were no consistent
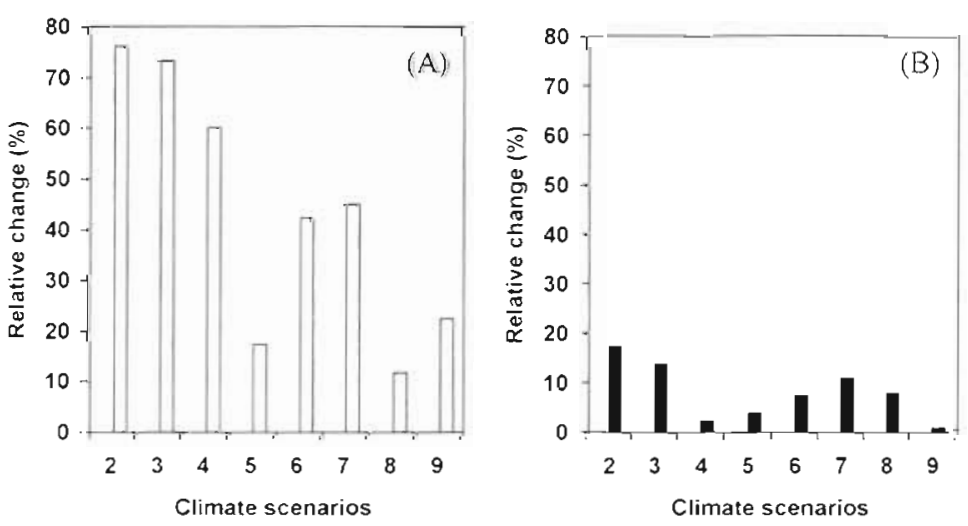

Fig. 6. Relative changes in the mean of degree days (A) and solar radiation $(B)$ for the period April to September compared to the baseline climate, as predicted by the climate scenarios. $10^{\circ} \mathrm{C}$ was used as the base temperature for the calculation of degree days 
Fig. 7. Relative changes in the mean value (A, C) and coefficient of variation $(B, D)$ of fruit dry matter as compared to the baseline climate, as predicted by the climate scenarios for $\mathrm{cv}$. Sangiovese $(\mathrm{A}, \mathrm{B})$ and $\mathrm{cr}$. Cabernet S. (C, D)
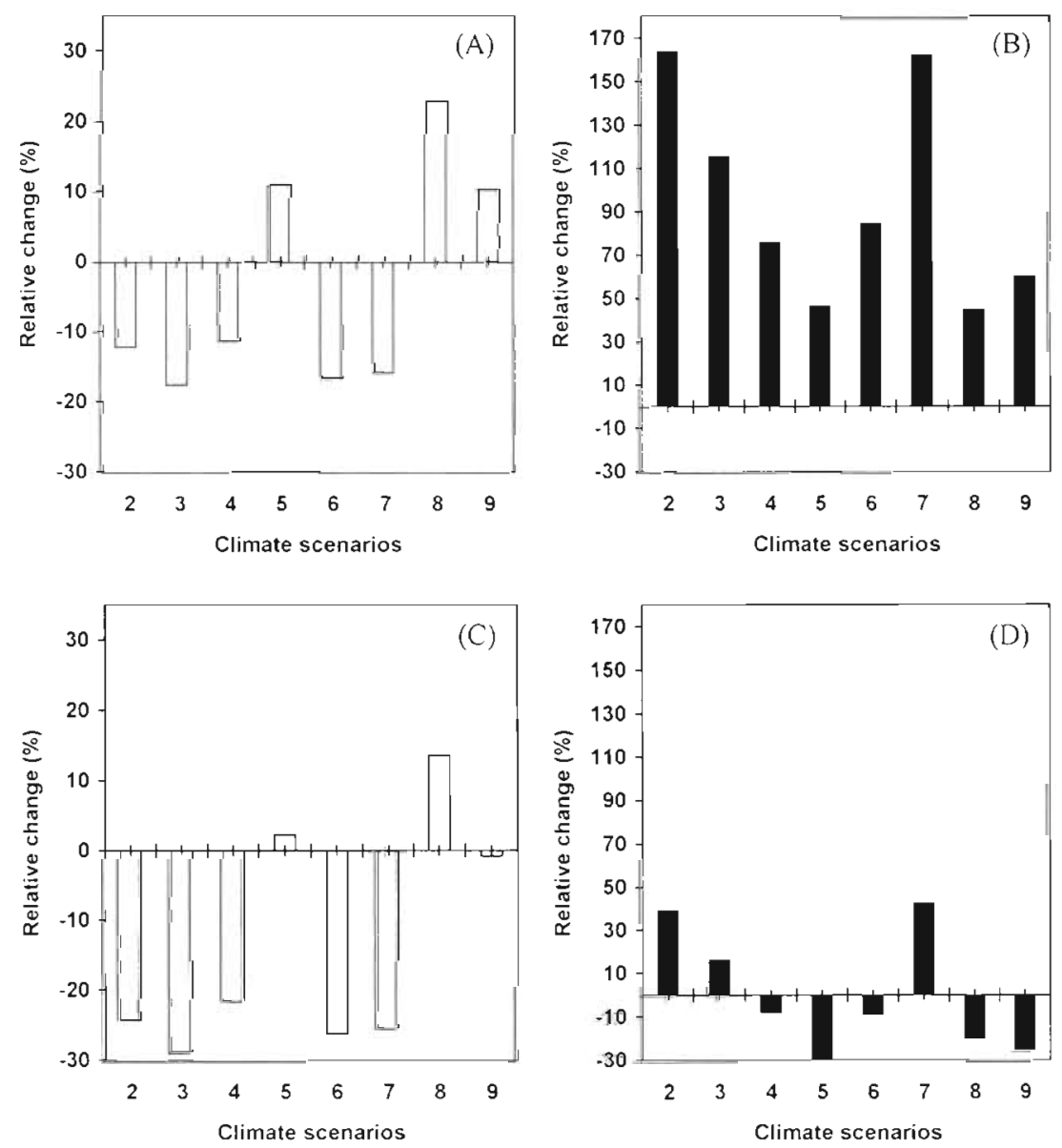

changes in the variability of growth components in the different scenarios for cv. Cabernet S. (Figs. $7 \& 8$ ).

\section{DISCUSSION AND CONCLUSIONS}

It is evident that the predicted effect of climate change on mean yield and yield variability of grapevine strongly depended on the GCM selected, the variety chosen and the introduction of changes in climatic variability. In particular, if we consider scenarios with the 'same $\mathrm{CO}_{2}$ emission' (Scenarios 5 and 8, and Scenarios 6 and 9) obtained from different GCMs we can observe that: (1) with GFDL scenarios the mean fruit dry matter was higher than in the baseline climate (Table 6a); and (2) no consistent changes in mean fruit dry matter were predicted with UKTR (Table 6a). Such a difference is obviously associated with the larger temperature changes predicted by the UKTR scenarios than by the GFDL scenarios (Fig. 6). But when yield variability is taken into account both GCMs predicted consistent increases (Table 6a).

Comparison between varieties showed that different adaptations to climate change may occur in terms of
Table 6. Relative changes in the mean and $\mathrm{CV}$ of fruit dry matter from the baseline climate for different (a) GCMs, (b) varieties and (c) scenarios with and without changes in variability of weather sequences

\begin{tabular}{|c|c|c|}
\hline & \multicolumn{2}{|c|}{$\begin{array}{l}\text { Relative change in } \\
\text { fruit dry matter }(\%)\end{array}$} \\
\hline & Mean & $\mathrm{CV}$ \\
\hline \multicolumn{3}{|l|}{ (a) GCMs } \\
\hline UKTR3140a & 6.61 & 8.73 \\
\hline UKTR6675a & -21.47 & 37.70 \\
\hline GFDL2534a & 18.20 & 12.41 \\
\hline GFDL5564a & 4.75 & 17.45 \\
\hline \multicolumn{3}{|l|}{ (b) Varieties } \\
\hline Sangiovese & -3.63 & 94.18 \\
\hline Cabernet S. & -13.91 & 0.80 \\
\hline \multicolumn{3}{|c|}{ (c) Climatic variability } \\
\hline UKHIV & -18.17 & 101.44 \\
\hline UKHI & -23.13 & 65.94 \\
\hline UKTR6675a & 6.61 & 8.73 \\
\hline UKTR6675av & -21.47 & 37.70 \\
\hline
\end{tabular}

mean yield and yield variability. Sangiovese showed a better adaptation in terms of mean yield (increase in 

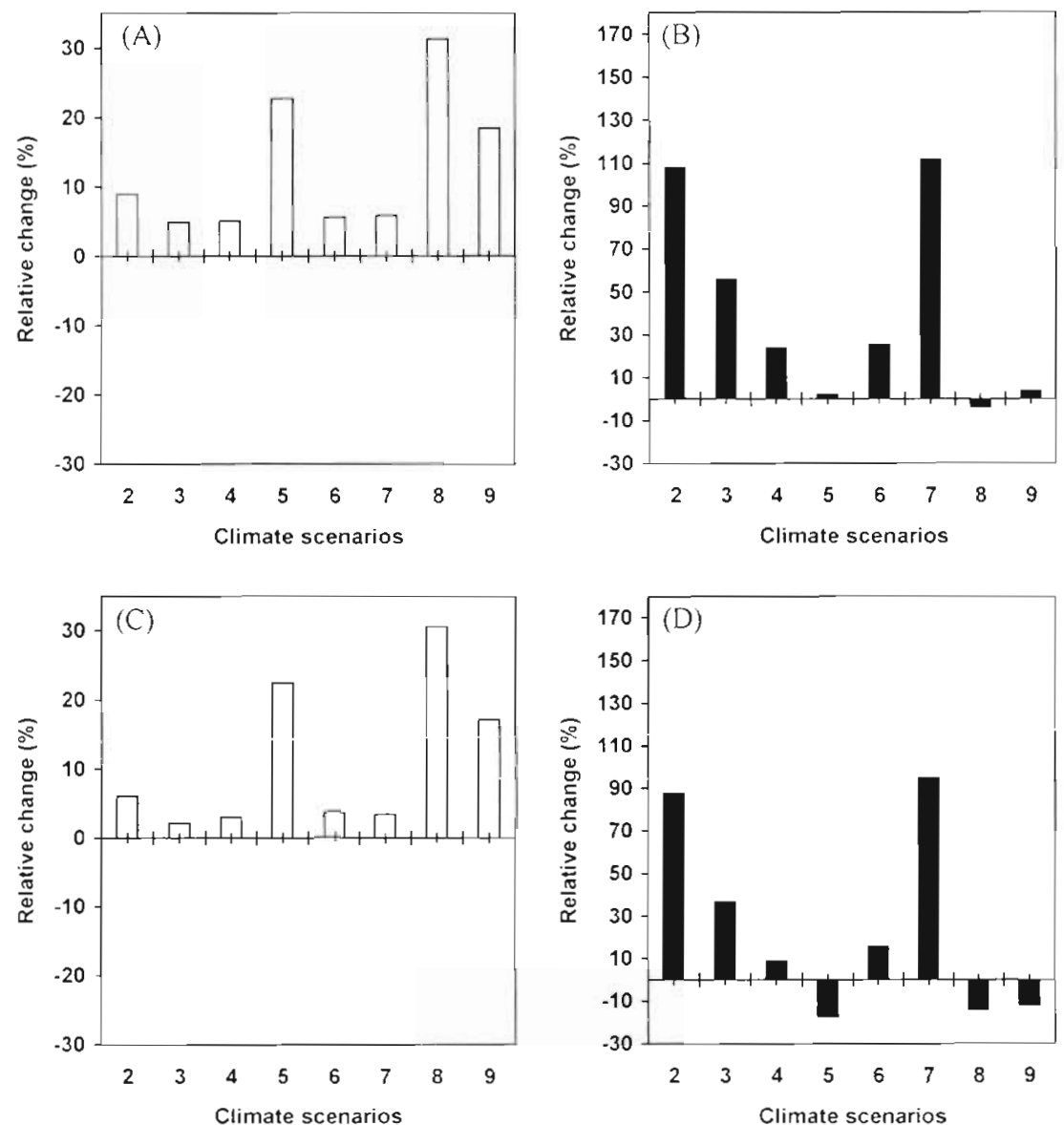

Fig. 8. Relative changes in the mean value (A, C) and coefficient of variation $(B, D)$ of total dry matter compared to the baseline climate as predicted by the climate scenarios for $C V$. Sangiovese (A, B) and $c V$. Cabernet S. (C, D)

mean fruit dry matter), but a worse adaptation in terms of yield variability (increase in CV) (Table 6b).

The effect of changes in climatic variability on yield and yield variability was clearly evident for both equilibrium and transient scenarios (Table 6c). Detailed examination of cumulative distributions of fruit yield for scenarios with and without changes in variability of weather sequences (Fig. 10; Scenarios 2-3 and 6-7) showed that a change in the variability of weather sequences did not substantially affect the average yield values (little shift in CDP), but substantially affected the variability of yield (less negative slope). This was due to an increase in both years with high yields and years with poor yields.

Overall, simulations did not provide a conclusive answer to the question of whether the potential negative
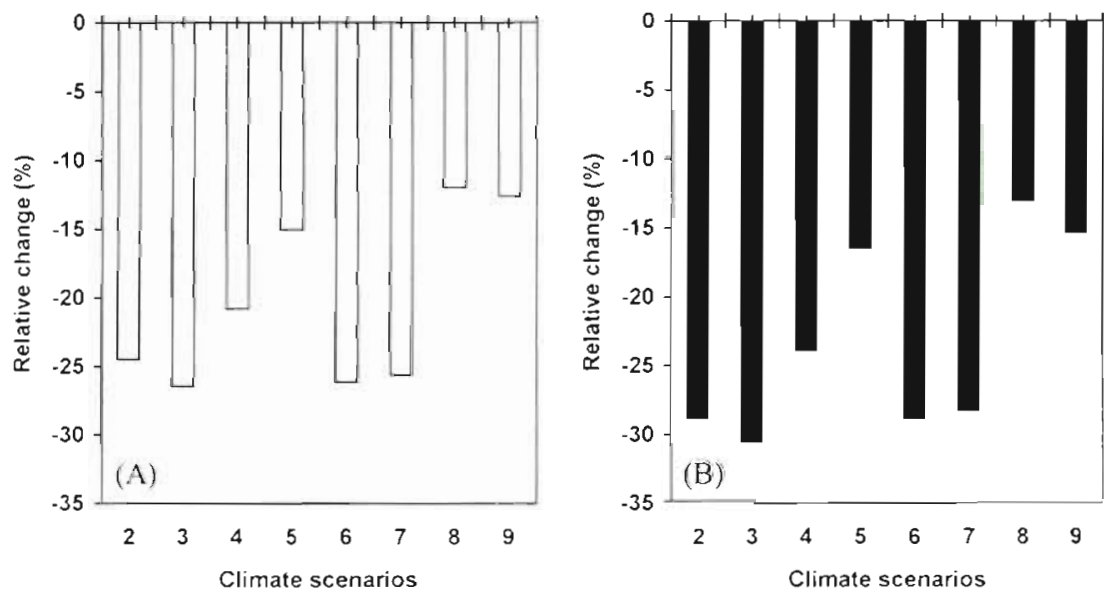

Fig. 9. Relative changes in the final value of fruit biomass index (FBI) for cr. Sangiovese (A) and cv. Cabernet S. (B) compared to the baseline value, as predicted by the model for different climate scenarios 

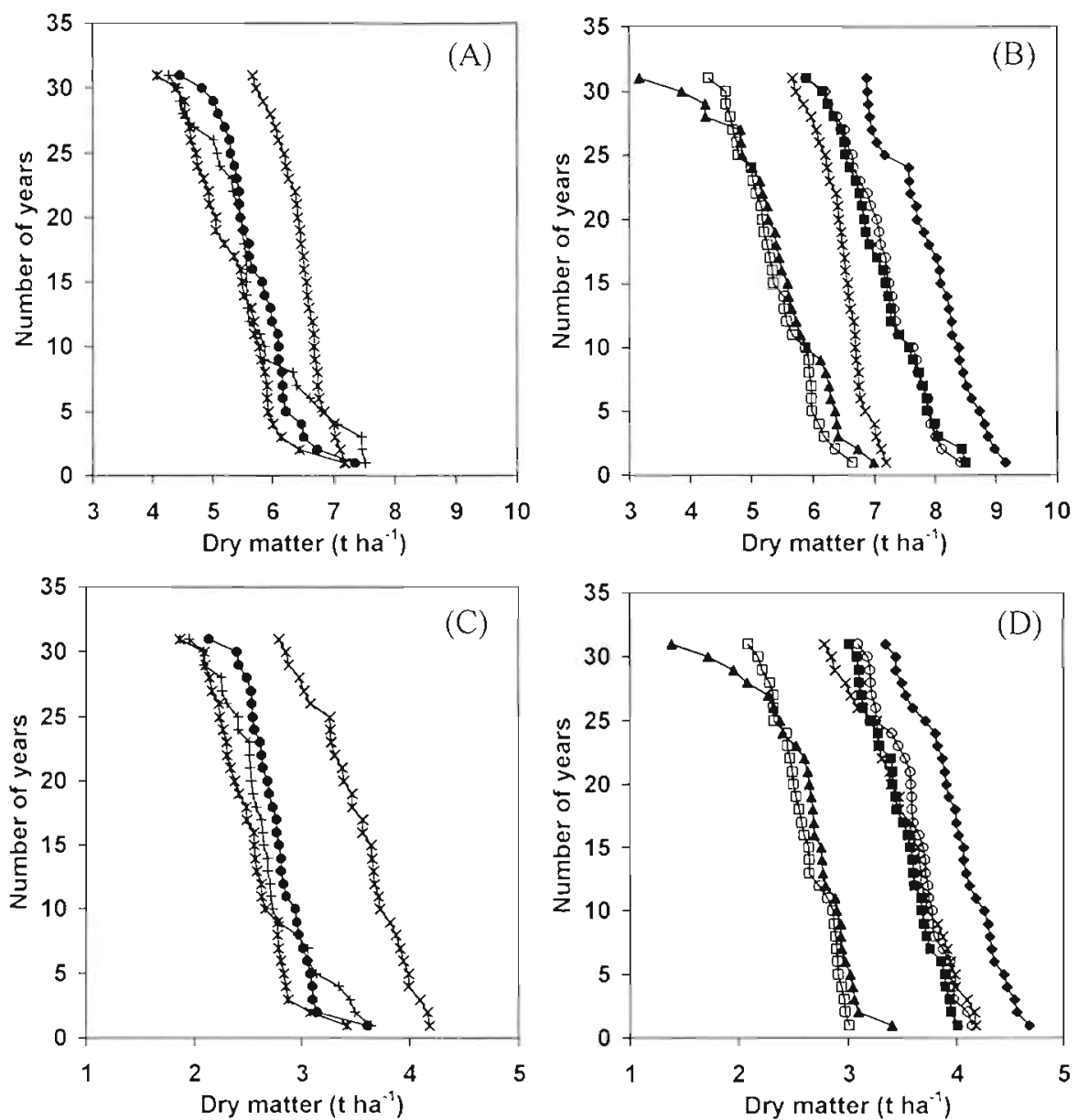

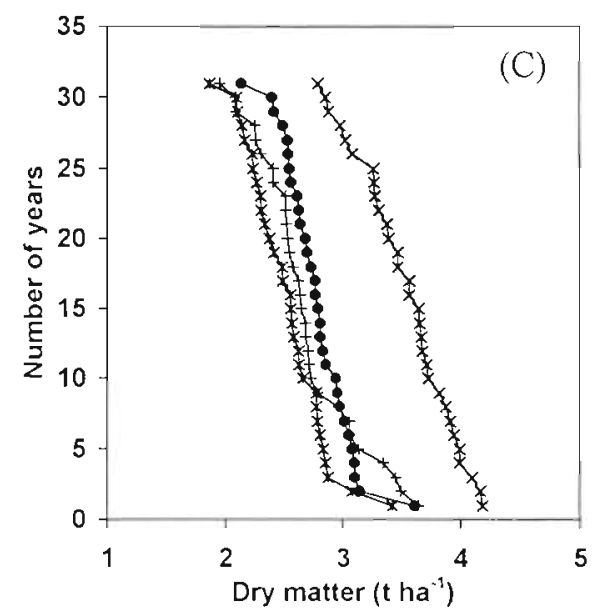

Fig. 10. Cumulative distribution plot (CDP) of fruit dry matter as predicted by the climate scenarios for $c v$. Sangiovese $(A, B)$ and cv. Cabernet S. (C, D). Scenarios: (x) $1,(+) 2$, $(*) 3,(\bullet) 4,(0) 5,(\square) 6,(4) 7,(\bullet) 8$, (a) 9

LITERATURE CITED

effects of the warmer temperatures predicted by the climate change scenarios will be compensated for by $\mathrm{CO}_{2}$-fertilization effects under climate change. However, these highlighted the fact that year-to-year variability in grapevine yields, either with or without changes in climatic variability, will increase in response to global environmental change. The difference between very high yields achievable in good years under increased atmospheric $\mathrm{CO}_{2}$ concentrations and lower yields in bad years will be larger than at present. Such an increase in yield variability would neither guarantee the quality of wine in good years nor meet the demand for wine in poor years, thus implying a higher economic risk for growers. Since this substantial increase in yield variability is not likely to be restricted to grapevine (Kenny et al. 1993, Harrison et al. 1995) we may already predict that world-wide efforts to stabilise food supplies will be required in the future.

Acknowledgements. We thank Mario Lanini and Lorenzo Seghi for technical assistance in data processing. This work was completed as part of a project funded by the European Commission's ENVIRONMENT Programme (Contract number: EV5V-CT92-0294).
Amir J, Sinclair TR (1991) A model of the temperature and solar-radiation effects on spring wheat growth and yield. Field Crops Res 28:47-58

Barrow EM, Semenov MA (1995) Climate change scenarios with high temporal and spatial resolution for agricultural applications. Forestry 68:349-360

Barrow E, Semenov MA, Hulme M (1995) Construction of scenarios of climate change and climatic variability at the site and regional scales: construction of site-specific models. In: Harrison PA, Butterfield RE, Downing TE (eds) Climate change and agriculture in Europe: assessment of impacts and adaptations. Research Report No. 9, Environmental Change Unit, University of Oxford, p 206-220

Bindi M, Fibbi L, Gozzini B, Orlandini S, Miglietta F (1995a) Modelling the effects of climate change and climatic variability on crops at the site scale: effects on grapevine. In: Harrison PA, Butterfield RE, Downing TE (eds) Climate change and agriculture in Europe: assessment of impacts and adaptations. Research Report No. 9, Environmental Change Unit, University of Oxford, p 30-45

Bindi M, Fibbi L, Gozzini B, Orlandini S, Miglietta F (1995b) Experiments on the effects of increased temperature and/or elevated concentrations of carbon dioxide on crops: mini Free Air Carbon dioxide Enrichment (FACE) experiment on grapevine. In: Harrison PA, Butterfield RE, Downing TE (eds) Climate change and agriculture in Europe: assessment 
of impacts and adaptations. Research Report No. 9, Envirommental Change Unit, University of Oxford, p 125-137

Calo' A (1970) Ricerche sulla variabilita' di alcune caratteristiche fenologiche nella Vitis vinifera L. I contributo Att Acc Ital Vite Vino 22:37-51

Coombe BG (1988) Grapevine phenology. In: Viticulture, Vol 1, Chap 7 Australian Industrial Publishers, Adelaide, p $139-153$

Harrison PA, Butterfield RE, Downing TE (eds) (1995) Climate change and agriculture in Europe: assessment of impacts and adaptations. Research Report No. 9. Environmental Change Unit, University of Oxford

Kenny GJ, Harrison PA (1992) The effects of climate variability and change on grape suitability in Europe. J Wine Res $3(3): 163-183$

Kenny GJ, Harrison PA, Parry ML (eds) (1993) The effects of climate change on agricultural and horticultural potential in Europe. Research Report No. 2, Environmental Change Unit, University of Oxford

Kimball BA, Mauney JR, Nakayama FS, Idso SB (1993) Effects of increasing atmospheric $\mathrm{CO}_{2}$. Vegetatio 104/105:65-75

Miglietta F, Gozzini B, Orlandini S (1992) Simulation of leaf appearance in grapevine. Viticult Enol Sci 47:41-45

Editor: G. Esser, Gießen, Germany
Muchow RC, Sinclair TR, Bennett JM (1990) Temperature and solar radiation effects on potential maize yield across locations. Agron J 82:338-343

Orlandini S, Bindi M, Gozzini B (1993) Effect of $\mathrm{CO}_{2}$-induced climatic change on viticultural environments of cool climate regions of Italy. Viticult Enol Sci 48:81-85

Racsko P, Szeidl L, Semenov MA (1991) A serial approach to local stochastic weather models. Ecol Model 57:27-41

Ritchie JT, Otter S (1984) CERES-wheat: a user-oriented wheat yield model. AGRISTARS Publication No. YM-U304442-JSC-18892

Rogers HH, Dahlman RC (1993) Crop responses to $\mathrm{CO}_{2}$ enrichment. Vegetatio 104/105:117-131

Sinclair TR, Rawlins SL (1993) Inter-seasonal variation in soybean and maize yields under global environmental change. Agron J 85:406-409

Spaeth SC, Sinclair TR, Ohnuma T, Konno S (1987) Temperature, radiation, and duration dependence of high soybean yields: measurement and simulation. Field Crops Res 16 : $297-307$

van Keulen H, Seligman NG (1987) Simulation of water use, nitrogen nutrition and growth of a spring wheat crop. PUDOC, Wageningen

Manuscript first received: February 6, 1996

Revised version accepted: July 4, 1996 